\title{
Identification of the Major Hydrological Threats for Two Clay Pan Wetlands in the South West of Australia
}

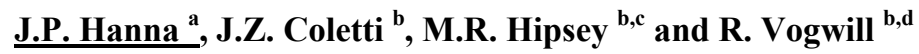 \\ ${ }^{a}$ Water Resources Division, WorleyParsons Consulting Practice 250 St Georges Terrace Perth WA \\ Email: jonathan.hanna@worleyparsons.com. \\ ${ }^{b}$ School of Earth and Environment, The University of Western Australia, 35 Stirling Hwy, Crawley, Western \\ Australia, 6009 \\ ${ }^{c}$ Centre for Ecohydrology, School of Environment Systems Engineering, The University of Western Australia, \\ 35 Stirling Hwy, Crawley, Western Australia, 6009 \\ ${ }^{d}$ Department of Environment and Conservation, 17 Dick Perry Avenue, Kensington, Western Australia, 6983
}

\begin{abstract}
This study presents the findings of a wetland ecohydrological model (WET-0D), used to recreate a historical water regime and predict the future water regime for two clay pan wetlands in South West Western Australia. WET-0D simulates the major hydrological fluxes through three conceptual water storages including the open water/lake, and surrounding unsaturated and saturated zones. Groundwater - soil water balance - vegetation (GSV) dynamics are modelled with plant biomass simulated as three functional vegetation groups with differing water uptake strategies and dependence on water availability. The wetland model was driven by a simple catchment water balance model, using historical climate data from the Bureau of Meteorology (BoM). To simulate the potential impact of climate change on wetland ecohydrology, statistically downscaled output from a Global Climate Model (GCM), based on the IPCC SRES A2 scenario, was used to drive the models to predict potential future water regimes. This allowed us to gain an insight of the impact of projected drying climate on the clay pan ecosystems.
\end{abstract}

Although both clay pan catchments experience very similar climates, differences in the partitioning of rainfall and subsequent flow generation, due to different vegetation, soil type and topography, results in dissimilar hydrological regimes. Differences in the hydrological regimes alter the way predicted climate change affects water flux and hydroperiod (period of surface flooding of a wetland) in both clay pan systems. Historically, the modelling predicts the lake level in the North East clay pan is more dependent on overland flow, while the South West clay pan is more dependent on shallow groundwater flow from a seasonal aquifer. Under a drying climate the modelling predicts, the South West clay pan will become increasingly overland flow dependent. However, the shallow groundwater inputs to the clay pan prolong inundation by reducing the rate of seepage from the clay pan. The partial clearing of the catchment area for the South West clay pan has maximised groundwater recharge efficiency allowing maintenance of ecological water requirements under a drying climate. The North East clay pan is under greater threat due to the reliance of surface water inflow and the lack of groundwater input due to differences in catchment characteristics.

Keywords: Wetland Model, Climate Change, Water Balance, Groundwater Surface Water interaction. 


\section{INTRODUCTION}

There has been a substantial shift in winter rainfall in the South West of Western Australia (SWWA) since the 1970s. A decrease in winter rainfall of $15-20 \%$, has resulted in a $40-50 \%$ reduction in surface run-off (Charles et al., 2007; Petrone et al., 2010). The Wheat Belt region of SWWA has numerous semi-arid, highly biodiverse wetland systems, that are threatened by the steep reduction in winter rainfall. It is known that semi-arid environments are sensitive to altered hydrology due to the tight coupling of water availability and vegetation dynamics (Tietjen et al., 2010); however, it remains unclear how changes in rainfall will manifest in wetland ecohydrological dynamics. The Drummond Nature Reserve (DNR) is located in the central agricultural region of the Wheat Belt $\left(31^{\circ} 18^{\prime} 54.57^{\prime \prime} \mathrm{S} ; 116^{\circ} 24^{\prime} 28.06^{\prime \prime} \mathrm{E}\right)$, and consists of two clay pan wetlands. The purpose of this study is to firstly understand the historic water balance of each clay pan wetland system, and secondly to test the sensitivity of the wetland systems to climate change. In order to meet these aims, we apply a novel wetland ecohydrological model to explore the hydrological controls on the wetland water balance and vegetation response, to estimate the effect of predicted climate change on clay pan hydrology. The results of the study will enable effective management measures and conservation plans to preserve the Ecological Water Requirements (EWR) for the high value biodiversity assets in the reserve.

\section{STUDY SITE AND DATA COLLECTION}

The DNR catchment experiences a semi-arid climate with hot dry summers and cool wet winters with an annual rainfall of between 440 and $560 \mathrm{~mm}$ and an annual evaporation rate of approximately $1,800 \mathrm{~mm}$ (BoM, 2011). Approximately 50\% of the South West clay pan catchment area (167 ha) has been cleared for agriculture while the North East catchment area (119 ha) remains uncleared. There are two major soil units: a sandy clay/laterite unit (overland flow dominated) and a medium to coarse grained sand unit (infiltration dominated). The South West clay pan catchment has a much larger fraction of the sand unit compared to the North East clay pan catchment. Daily rainfall data used in the simulations was obtained from the Bureau of Meteorology (BoM) weather station at Bolgart (Station ID 10009) located $14 \mathrm{~km}$ east of DNR. Data (1960 2010) from the BoM weather station at Northam (Station ID 10111) was used to supplement the Bolgart data set where there were gaps in annual rainfall and other climatic parameters. Statistically downscaled Global Climate Model (GCM) data is used (Charles et al., 2007) to demonstrate the impact of projected climate change. In that study a Non-homogenous Hidden Markov Model (NHMM) was used to downscale atmospheric predictors from the GCM to multi-site daily rainfall values, and multiple linear regression was used to provide the rainfall depth (Charles et al., 2007). The climate model simulation is forced by the IPCC SRES A2 emission scenario which assumes a heterogeneous continually increasing global population with fragmented, slower and regionally orientated economic growth. Time-series of the down-scaled rainfall and temperature were applied from 2011 to 2040.

\section{MODEL DESCRIPTION}

WET-0D, described in (Coletti et al., submitted), was used to model the clay pans at DNR. WET-0D has been derived from a water balance model developed by Farmer et al. (2003), but differs where instead of stream flow being the outlet for the model, a height-volume relationship representing the wetland is included and water is partitioned dynamically into functional wetland zones (Figure 1, Coletti et al., 2011). The wider contributing catchment area $(A c)$ is modelled using the approach identified in Farmer et al. (2003), where a multiple bucket approach introduces the required heterogeneity in soil types and plant water use to provide the sub-surface and overland inflows required by the wetland models (Figure 2).

WET-0D models hydrological fluxes through a wetland system by linking three locally relevant conceptual water storages including the open water/lake (L), unsaturated zone (U) and the saturated zone (S) (Figure 1; Coletti et al., submitted). The shape of the lake bed is derived from LIDAR topographical data, which was used to build a Digital Terrain Model (DTM) for both catchments. The height-area-volume data was subsequently plotted and used to extract a $3^{\text {rd }}$ order polynomial equation to provide the geometric relationships for each clay pan. The lake bed is in the centre of the model domain and the runoff finds the lake depression and the resulting volume either pools on the surface, is lost as evapo-transpiration or redistributed via seepage. The lake water balance is solved on a daily time step using a mass balance approach:

$$
\frac{d L}{d t}=P_{L}+Q_{c}+Q_{w}-Q_{S}-E_{L}
$$


where $P_{L}$ is the precipitation rate that enters the lake $\left(\mathrm{m}^{3} \mathrm{~d}^{-1}\right)$, which is equal to the effective precipitation, $P_{e}$ $\left(\mathrm{m} \mathrm{d}^{-1}\right)$, multiplied by the lake area. Effective precipitation is the precipitation that reaches the ground after being intercepted by the canopy, represented by Leaf Area Index $\left(L A I_{n}\right)$. Inputs into the lake are the sum of the flow $\left(\mathrm{m}^{3} \mathrm{~d}^{-1}\right)$ entering from the external catchments, $Q_{c}$, and sum of overland flow generated within the WET-0D domain, $Q_{w}$ (Coletti et al., submitted). Potential evaporation, $E_{0}\left(\mathrm{~m} \mathrm{~d}^{-1}\right)$ is calculated over the openwater area according to Penman-Monteith using cloud cover and solar radiation on a cloudless day as an approximation for the incident solar radiation (Kasten and Czeplak, 1980) and $E_{0}$ is adjusted using the pan-tolake correction factor $c$ (set to 0.8 ), such that:

$E_{L}=c E_{0} A_{L}$.

The wetland model is driven by the external climate inputs including relative humidity (\%), precipitation (m), air temperature $\left({ }^{\circ} \mathrm{C}\right)$, solar radiation $\left(\mathrm{MJ} / \mathrm{m}^{2} / \mathrm{d}\right)$ and wind speed $(\mathrm{m} / \mathrm{s})$ which are supplied from the available data or down-scaled GCM output. When the water table level (m), $h_{S}$, is higher than the lake level (m) $h_{L}$, the terrestrial area $\left(\mathrm{m}^{2}\right)$ is further divided into an unsaturated $\left(A_{U}\right)$ and saturated areas $\left(A_{S}\right)$. The lake area, $A_{L}$ $\left(\mathrm{m}^{2}\right)$, is calculated using the height/volume relationship within the lake derived from the DTM. The total area of the wetland, $A_{W}\left(\mathrm{~m}^{2}\right)$, is constant and equals to the sum of all surface areas with the lake and water table levels defining the wetland as lake $(L)$, saturated $(S)$ and unsaturated soils $(U)$ areas, such that $A_{W}=A_{S}+A_{U}+A_{L}$. $Q_{s}$ is the seepage flow $\left(\mathrm{m}^{3} \mathrm{~d}^{-1}\right)$ through the area of the lake base, $A_{S L}$, and the free saturated area, $A_{S}\left(\mathrm{~m}^{2}\right) . Q_{s}$ is defined as being proportional to the hydraulic gradient between lake and the water table, based on an hydraulic conductivity, $K_{s}\left(\mathrm{~m} \mathrm{~d}^{-1}\right)$, and the head difference according to Darcy's Law. The seepage volume $\left(\mathrm{m}^{3} \mathrm{~d}^{-1}\right)$ is positive when flowing from the lake to the water table and negative when groundwater is discharging to the lake:

$$
Q_{s}=2 K_{s}\left(h_{L}+h_{B}-h_{S}\right) \frac{\left(A_{S L}+A_{S}\right)}{r_{W}}
$$

Runoff from the wetland $\left(Q_{w}\right)$ is the sum of the flow generated from infiltration $\left(Q_{i e}\right)$ and saturation $\left(Q_{s e}\right)$ excess mechanisms $\left(\mathrm{m}^{3} \mathrm{~d}^{-1}\right)$. Infiltration excess is calculated as the amount of precipitation reaching the ground that is greater than the infiltration capacity of the soil.

\subsection{Soil Water Storage}

The effective volume of water present in the soil, $S\left(\mathrm{~m}^{3}\right)$, fluctuates as a function of the volume that infiltrates the soil, $I$, the seepage, $Q_{S}$, the

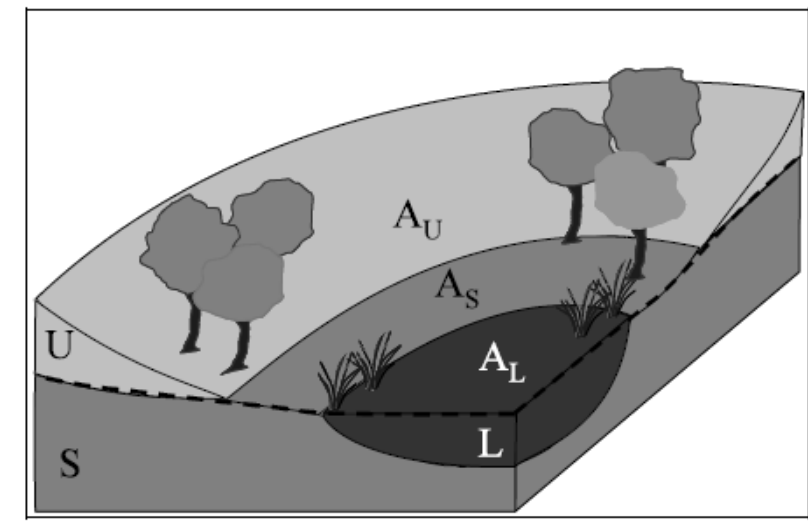

Figure 1. Conceptual model of WET-0D volume of groundwater discharge lost to the underlying aquifer, $Q_{s s}$, the total evapo-transpiration from the ground, $E_{\text {soil }}\left(\mathrm{m}^{3} \mathrm{~d}^{-1}\right)$, and the saturation excess runoff, $Q_{\text {se }}$, summarised as:

$$
\frac{d S}{d t}=I \pm Q_{S}-Q_{s s}-E_{\text {soil }}-Q_{s e}
$$

The groundwater flow, $Q_{s s}\left(\mathrm{~m}^{3} \mathrm{~d}^{-1}\right)$, is adapted from Farmer et al., (2003) and is defined as:

$$
Q_{s s}=\left(\alpha_{G} h_{s}\right)^{\beta_{G}} A_{W}
$$

where $\alpha_{G}$ is arbitrarily defined as equal to $10^{-4}$ and $\beta_{G}$ is the flow recession parameter. The total water store $\left(\mathrm{m}^{3}\right)$ of each soil column is comprised of saturated $\left(S_{S A T}\right)$ and unsaturated regions $\left(S_{U S}\right)$, such that:

$$
\begin{aligned}
& \frac{d S_{U S}}{d t}=I-E_{U}-E_{b U}-Q_{p} \pm Q_{c} \\
& \frac{d S_{S A T}}{d t}=Q_{p} \pm Q_{s}-E_{S}-E_{b S}-Q_{s e}-Q_{s s} \pm G W_{c}
\end{aligned}
$$

where $Q_{P}$ is percolation $\left(\mathrm{m}^{3} \mathrm{~d}^{-1}\right)$. Infiltration $\left(\mathrm{m}^{3} \mathrm{~d}^{-1}\right), I$, is a function of soil moisture, $\theta$, such that at $100 \%$ soil moisture no infiltration occurs and saturation excess is generated, and alternatively once the soil moisture exceeds the field capacity $\left(f_{c}\right)$ gravity drainage occurs from $S_{U S}$ to $S_{S A T}$ to reduce the unsaturated zone 
moisture content to fc within the day. Soil type affects the infiltration rate through saturated hydraulic conductivity, $K_{s}$, and the arbitrary recession coefficient for infiltration, $k_{I}$. Percolation of water from the vadose to the saturated zone, $Q_{p}\left(\mathrm{~m}^{3} \mathrm{~d}^{-1}\right)$, takes place when the volume of water in the unsaturated zone surpasses the volume that can be held by the soil despite the action of gravity. This threshold is approximated by taking the total unsaturated zone capacity $U_{c}\left(\mathrm{~m}^{3}\right)$, multiplied by the soil moisture at field capacity. Biomass, $B(\mathrm{~kg} \mathrm{C})$, dynamics are governed by the rate of photosynthesis, $\Pi_{A}\left(\mathrm{~kg} \mathrm{C} \mathrm{m}^{-2} \mathrm{~d}^{-1}\right)$, losses due to litterfall, $L_{l}\left(\mathrm{~kg} \mathrm{C} \mathrm{d}^{-1}\right)$, root death, $R_{d}\left(\mathrm{~kg} \mathrm{C} \mathrm{d}^{-1}\right)$ and respiration, $R\left(\mathrm{~kg} \mathrm{C} \mathrm{d}^{-1}\right)$ defined as in Running and Coughlan (1988). Biomass changes in time, but is spatially stationary. As the spatial extent of each area with distinct hydrological function $(U, S$ and $L)$ changes, the amount of any vegetation type $i$ present at each location changes accordingly (Coletti et al., submitted). The balance equation for any vegetation type is therefore:

$$
\frac{d B_{i, n}}{d t}= \begin{cases}\prod_{A i, n} A_{n}-L_{l i, n}-R_{i, n}-R_{d i, n}+D_{i, n-1} \frac{d A_{n}}{d t} & \text { if } \frac{d A_{n}}{d t}>0 \\ \prod_{A i, n} A_{n}-L_{l i, n}-R_{i, n}-R_{d i, n}+D_{i, n} \frac{d A_{n}}{d t} & \text { if } \frac{d A_{n}}{d t}<0\end{cases}
$$

$D$ is the vegetation biomass density per unit area $(=B / A)$ and $A_{n}$ is the area of the $n^{\text {th }}$ wetland zone $\left(\mathrm{m}^{2}\right)$. The rate of carbon litter production, $L_{l}$, is assumed to be $0.31 \%$ of the biomass (Friend et al., 1997). Each plant type $i$ can survive in a particular hydrological environment $(n=U, S$ or $L)$ though grow optimally in the hydrological environment that best matches their respective water uptake strategy. The vegetation groups adopted in this study include phreatophytic trees, terrestrial shallow rooted annual grasses and wetland macrophytes. The shallow rooted grasses are exclusively adapted to unsaturated soils; macrophytes require standing water or saturated soils, and the phreatophytic trees are adapted to extract water from both below the water table level and within the unsaturated zone (Coletti et al., submitted).

\subsection{External Catchments}

Both WET-0D models include external catchment inflow in the form of groundwater, $G W_{c}\left(\mathrm{~m}^{3} / \mathrm{d}\right)$ and overland flow, $Q_{c}\left(\mathrm{~m}^{3} / \mathrm{d}\right)$ using a simplified rainfall-runoff model (Farmer et al., 2003), Catchment heterogeneity was modelled by adopting a multiple bucket approach for the $A_{C}$ component (Figure 2). The groundwater flow from the external catchment $\left(G W_{c}\right)$ was included in the

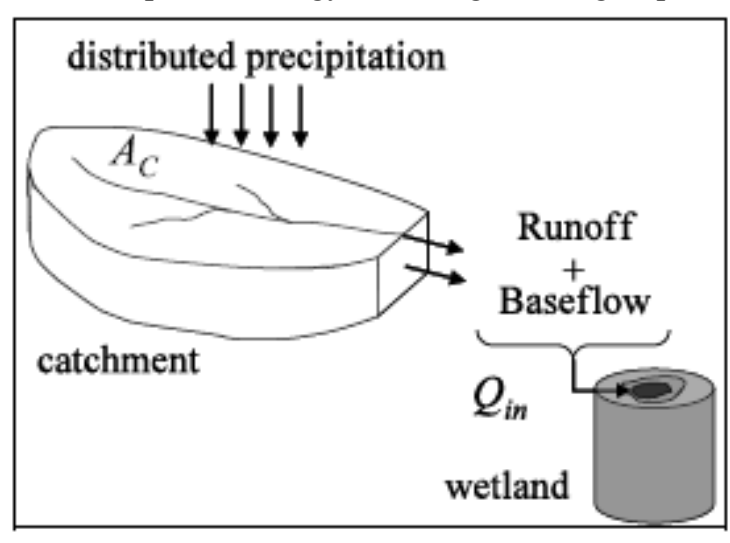

Figure 2. Conceptual model of the external model coupled with WET-OD wetland models as a contribution into the saturated zone, $S$. The surface flows generated in the lateritic catchment model was imported into the wetland model as a water volume addition to the vadose zone, where water is subsequently partitioned within the day depending on the soil mositure $(\theta)$ and field capacity $\left(f_{c}\right)$. Soil hydraulic parameters typical of sand and laterite including field capacity, wilting point $\left(\theta_{W}\right)$, hydraulic conductivity $\left(K_{s}\right)$ and recession factors $\left(k i, k p, \beta_{G}\right)$ are incorporated into each external catchment model. There are also specific vegetation parameters for each catchment model including optimum soil moisture, wilting point and effective rooting depth. The water balance for each external catchment is solved on a daily time step using precipitation $\left(P_{c}\right)$ and potential evapotranspiration (using Penmain Monteith) as function of temperature, wind speed, relative humidty and solar radiation. Effective precipation is calculated using a interception loss method described by Sivapalan et al., (1996). The South West clay pan model has two external catchments providing flow to the wetland domain (deep sand with shallow rooted annual pasture and lateritic soils with open Wandoo woodland). The North East claypan has one external catchment contributing flow (lateritic soils with open Wandoo woodland).

\subsection{Calibration}

Both wetland models were calibrated using water level logger data collected for both clay pans by the Department of Environment and Conservation (DEC) during 2009. Parameters of hydraulic conductivity, lake bed shape co-efficients, and infiltration, percolation and groundwater flow parameters, were iteratively optimised until the modelled hydrograph correlated with the equivalent observed hydrograph (Figure 3). Calibration error statistics using Scaled Root Mean Square, yielded values of $8 \%$ and $9 \%$ obtained for the South West clay pan and North East clay pan models respectively. 


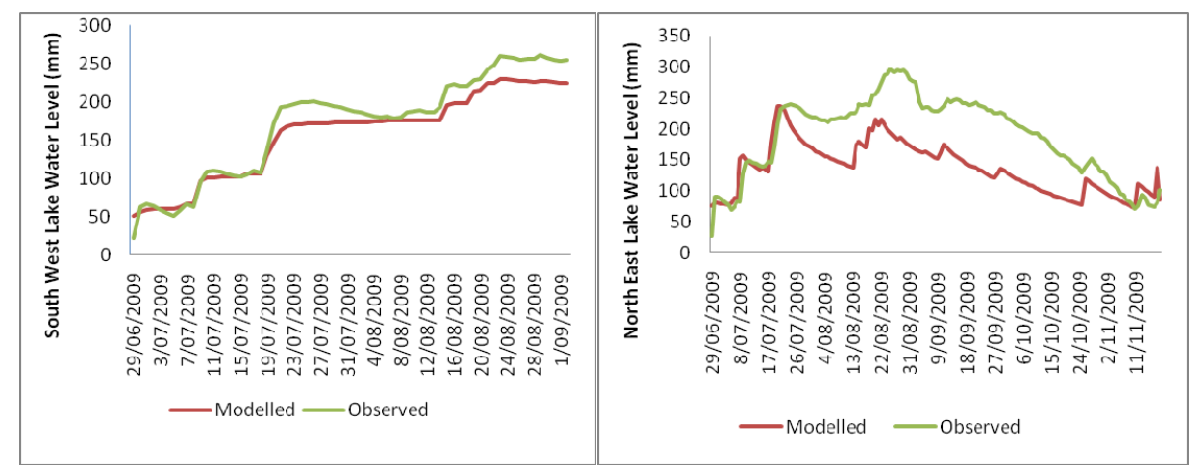

Figure 3. Calibration of lake levels for the South West and North East models.

\section{RESULTS}

The moving average of annual rainfall of the predicted climate shows a continuation of the "dry" post 1970's rainfall regime with an average annual rainfall of $415 \mathrm{~mm}$. There is an increase in average annual temperature for the future climate of approximately $2^{\circ} \mathrm{C}$. The future climate experiences a similar average annual rainfall as the post 1970's record but with a greater number of extreme high intensity rainfall events $\left(>Q_{i e}\right)$ and higher annual average temperatures (resulting in higher potential evapo-transpiration). This effectively reduces the soil moisture by increasing plant water uptake and reducing infiltration due to increased overland flow.

\subsection{Water Balance}

There is a shift in the water balance for both clay pans (Figures 4 and 5) as a result of the post 1970/2010 shift in rainfall. Lake level, the saturated (water table) and unsaturated depths for both models reflect the shift in daily rainfall post 1970/2010. There is a downward shift of $200 \mathrm{~mm}$ in average water table level for both wetlands post 1970/2010, which has implications for groundwater/surface water interactions. With a decline in saturated depth there is a corresponding increase in unsaturated depth for both wetlands post 1970. The overall average saturated depth, peak saturated depth and minimum saturated depth is higher for the South West wetland model due to external groundwater inflow. Post 1970, the difference is less pronounced between the two wetland domains, and the average peak water levels for both models show a similar trend. The average annual fluctuation (difference between the maximum and minimum levels) in the saturated and unsaturated water stores is similar between catchments, indicating a similar response to rainfall. The saturated depths continue to decline for both clay pans with a prolonged drying of the climate.

The differences between the models are most evident in the change in seepage flows over the simulation period. The overall average peak water table level for the South West clay pan is 1,084 $\mathrm{mm}$ and $947 \mathrm{~mm}$ for

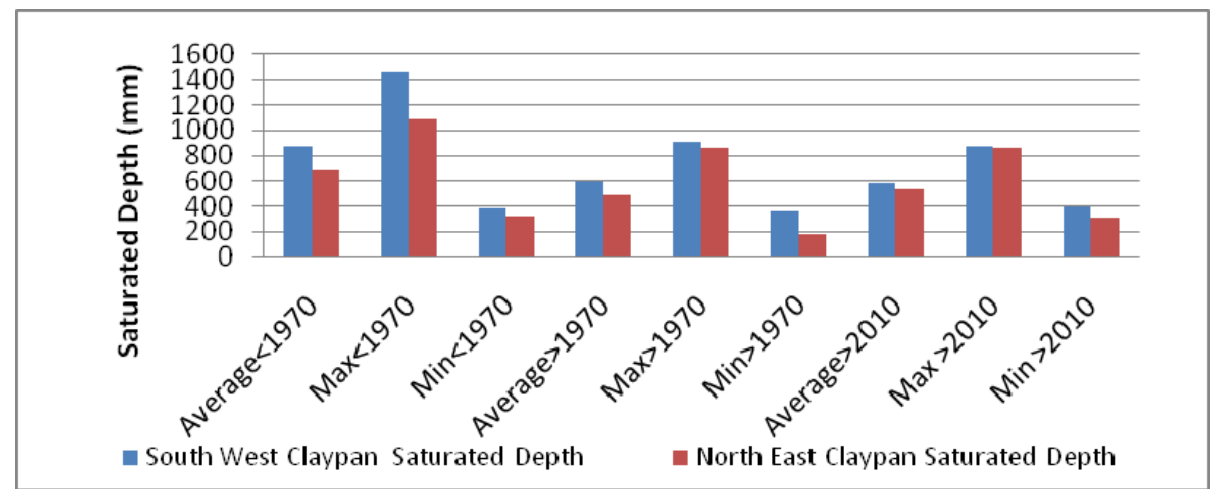

Figure 4. Comparsion of average water table (saturated depth) for both models.

the North East clay pan. The pre 1970 average maximum water table level is above 1,000 mm (threshold level for seepage to occur to the lake) with peak levels of over $1,500 \mathrm{~mm}$, above the highest lake level. Post 1970, the average peak water table is below $1,000 \mathrm{~mm}$ for both models, therefore there is shift from groundwater discharging to the lake to lake water discharging to the groundwater. This is particularly evident for the seepage flow in the South West clay pan. Groundwater discharge flows are more prominent pre 1970; post 1970, mostly groundwater recharge flows are observed. The North East clay pan has largely been a 
groundwater discharge lake over the entire simulation period. This trend continued in the post 2010 simulations. There is a greater fluctuation in annual lake level in the North East clay pan compared to the South West clay pan (by $>100 \%$ ).

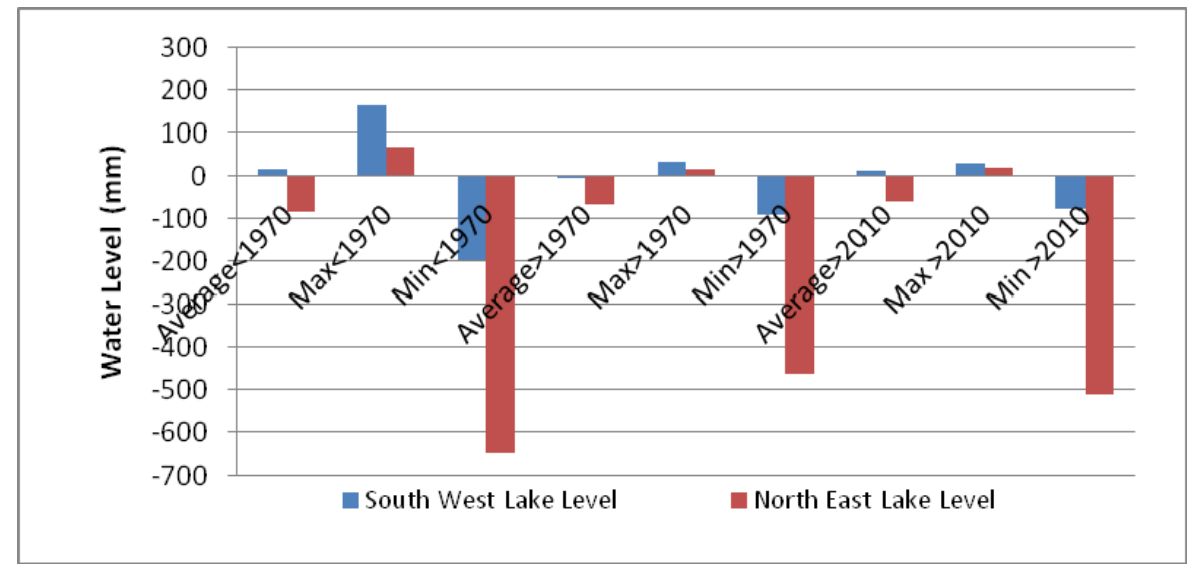

Figure 5. Comparsion of the average water level for both model domains.

The two external catchments for the South West clay pan wetland displayed different responses to precipitation. Due to the shallow soil profile and proximity to duricrust, the laterite catchment yielded higher overland flow compared to the deep sand profile of the cleared catchment. Post 1970, the modelling predicts a slight shift in groundwater flow and a lower frequency of overland flow events for the deep sand with shallow rooted annual pasture catchment. This persistence in groundwater flow contribution to the South West clay pan has led to a greater saturated depth (i.e. shallower water table) compared to the North East clay pan. The external catchment flow for the North East clay pan showed similar characteristics as the laterite model for the South West model, with overland flow dominating, the difference being a 50\% higher overland flow contribution due to the greater laterite catchment area.

\subsection{Vegetation Dynamics}

The vegetation dynamics correlate with the shift in the water regime, this is particularly evident for the wetland macrophytes and shallow rooted annual grasses. Under the projected future climate regime, the decrease in annual average rainfall, increase in high intensity storm events $\left(>Q_{i e}\right)$ and higher evapotranspiration demand decreased the moisture stored in the unsaturated zone and resulted in a decrease in LAI for the annual vegetation. Wetland macrophyte leaf area index (i.e. biomass) also responded to changes in the post 1970 and 2010 wetland water regime. The general decrease in lake area as a result of lower inundation depth directly correlates to the decrease in lake area and thus wetland macrophyte leaf area index. This was demonstrated more so for the North East clay pan, which dried out quickly due to the higher seepage loss as a result of the lower water table level. The comparatively higher water table level (due to enhanced recharge in the cleared sandy catchment) in the South West clay pan model meant that the rate of seepage from the wetland was slower and thus the inundation period was longer, resulting in greater persistence in LAI for wetland vegetation. The phreatophytic vegetation showed very little change in LAI as a result of drying climate, this was due to the water table always being within the effective rooting depth of the vegetation and thus providing sufficient water to prevent plant death.

\section{DISCUSSION AND CONCLUSIONS}

The external catchments provide the major difference in the hydrological functioning of both clay pans. The external catchments for the South West model contribute more groundwater flow to the South West clay pan, compared to the North East model. These sub-surface inflows are subject to less loss due to being below the evaporative depth and the plant water use depth. Recharge is enhanced with shallow rooted annual vegetation replacing phreatophytic vegetation. The sub-surface flows decreased the sensitivity of the wetland water balance to drying climatic conditions, and provided a more stable hydroperiod. The North East wetland model predicted that the catchment contributes the majority of clay pan inflow via overland flow. However, there is little storage of this water as it is readily evaporated from the soil and lake surface. The lower relative external groundwater flow contribution increased the sensitivity to drying climate by lowering the water table and increasing the rate of seepage from the lake, seen as the greater fluctuation in lake level for the North East clay pan. 
The differences in saturated storage dynamics between the models affect the direction of seepage, which is dependent upon the hydraulic gradient that exists between the water table and lake levels. The North East clay pan appears to have been largely a groundwater recharge lake over the simulation period. This is due to the large overland flow component entering the North East clay pan, which in turn increases the lake level above the surrounding water table resulting in groundwater recharge. The lake level in the North East model is sensitive to large rainfall events that result in the generation of overland flow. These are seen as large positive seepage flows for the North East clay pan resulting in spikes in saturated depth as lake water discharges to the water table. Pre 1970, the South West model does not show the same frequency of high magnitude surface water driven flow events. However, the overall saturated volume is greater due to groundwater flow from the external catchment. Due to lower annual rainfall post 1970, the water table declines in the South West model causing a shift in interaction from a groundwater discharge (gaining) to a groundwater recharge (losing) system. This trend is further enhanced due to changes in the rainfall temporal pattern predicted under climate change with an increase in extreme rainfall events. The high intensity events generate $Q_{i e}$ increasing external surface inflows. The change in rainfall temporal pattern will affect plant water use in the unsaturated and saturated storages and the pathway in which water enters the clay pans (i.e. as overland flow). The modelled vegetation dynamics reflect this decrease in unsaturated moisture with a decrease in shallow rooted annual grass LAI.

With climate change, the hydrology of the South West clay pan is becoming more like the North East clay pan (i.e. overland flow dominated). However, due to differences in the hydrological regimes in the South West model, the inundation period is prolonged. The higher inundation period supports the highly biodiverse aquatic macroinvertebrate community and wetland macrophyte species. The modelled LAI for the wetland vegetation for the South West clay pan persists for a longer duration compared to the North East clay pan due to the longer hydroperiod. Even though the North East clay pan has an uncleared catchment it is more sensitive to changing climate. In effect, the partial clearing of the recharge area for the South West clay pan has enabled only a slight reduction in recharge under a drying climate and thus providing less sensitivity to climate change and maintenance of EWRs for the dependent species. This study has demonstrated that two clay pans with similar climate require different conservation management strategies under a drying climate. An understanding of the hydrological regime is required to develop a strategy to maintain the EWRs for semi arid wetland systems, and revegetation may not always be the best strategy under a drying climate.

\section{REFERENCES}

Aydin, M., Yang, S., Kurt, N., Yano, T. (2005). Test of a simple model for estimating evaporation from bare soils in different environments. Ecological Modelling. 182: 91-105.

Bureau of Meteorology (2010). Climate Data Obtained online in November 2010. http://www.bom.gov.au/

Charles, S.P., Bari, M.A., Kitsios, A., Bates, B.C. (2007). Effect of GCM bias on downscaled precipitation and run-off projections for the Serpentine catchment, Western Australia. International Journal of Climatology. 27: 1673-1690.

Coletti, J.Z., Hipsey, M.R., Vogwill, R., Hinz, C. (2011). A minimalistic model for carbon cycling in wetlands. Proceedings of MODSIM 2011, Perth, Australia.

Coletti, J.Z., Hinz, C., Vogwill, R, Hipsey, M.R. (submitted). Behavioural insights into wetland biomass dynamics exploring soil, climate and vegetation controls in South Western Australia.

Farmer, D., Sivapalan, M., Jothityangkoon, C. (2003). Climate, soil, and vegetation controls upon the variability of water balance in temperate and semi arid landscapes: Downward approach to water balance analysis. Water Resources Research. 39. (2): 1035, doi:10.1029/2001 WR00328,2003.

Friend, A.D., Stevens , A.K., Knox, R.G. , Cannell, M.G.R. (1997). A process-based, terrestrial biosphere model of ecosystem dynamics (Hybrid v3.0). Ecological Modelling, 95: 249-287.

Kasten, F. and Czeplak, G. (1980). Solar and terrestrial radiation dependent on the amount and type of cloud. Solar Energy. 24: 177-189.

Petrone, K. C., Hughes, J. D., Van Niel, T. G., Silberstein R. P. (2010). Stream flow decline in southwestern Australia, 1950-2008, Geophysical Research Letters. 37: L11401.

Sivapalan, M., Ruprecht, J.K., Viney, N.R. (1996). Water and salt balance modelling to predict the effects of land use changes in forested catchments. 1. Small catchment water balance model. Hydrological Processes. 10: 393-411.

Skaggs, T., van Genuchten, M., Shouse, P., Poss J. (2006). Macroscopic approaches to root water uptake as a function of water and salinity stress. Agricultural Water Management, 86: 140 - 149.

Tietjen, B., Jeltsch, F., Zehe, E., Classen, N., Groengroeft, A., Schiffers, K., Oldeland, J. (2010). Effects of climate change on coupled dynamics of water and vegetation in drylands. Ecohydrology, 3: 226-237. 